\title{
Potência necessária para acionamento de uma colhedora de fluxo axial para feijão ${ }^{1}$
}

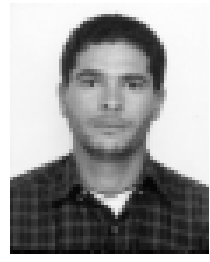

\author{
Cristiano M. A. de Souza2 ${ }^{2}$ Daniel M. de Queiroz ${ }^{3}$, Gutemberg P. Dias ${ }^{4}$ \& Francisco de A. de C. Pinto \\ 1 Parte da Dissertação de Mestrado do primeiro autor, apresentada à UFV \\ 2 DEA/UFV. CEP 36571-000, Viçosa, MG. Fone: (31) 3899-2853. E-mail: csouza@alunos.ufv.br (Foto) \\ 3 DEA/UFV. Fone: (31) 3899-1882. E-mail: queiroz@mail.ufv.br \\ ${ }^{4}$ CCTA/UENF. CEP 28015-620, Campos dos Goytacazes, RJ. Fone: (24) 2726-3858. E-mail: gpdias@uenf.br \\ 5 DEA/UFV. Fone: (31) 3899-1881. E-mail: facpinto@mail.ufv.br
}

Protocolo $107-3 / 7 / 2001$

\begin{abstract}
Resumo: O objetivo deste trabalho foi determinar a potência necessária para acionamento de uma colhedora de fluxo axial para feijão. Testes experimentais foram conduzidos, sendo determinados o torque e a rotação na tomada de potência do trator, a força necessária para arrastar a máquina, a velocidade de trabalho, a quantidade de produto colhido e o tempo necessário para colhê-lo. Para se estudar o comportamento das variáveis investigadas, realizaram-se análises de metodologia de superfície de resposta. A potência exigida no motor do trator para tracionar a colhedora, com carregamento máximo do tanque graneleiro, foi equivalente a $7,90 \mathrm{~kW}$ e o acionamento dos órgãos internos demandou 45,28 kW. A potência total exigida pela máquina foi de $53,18 \mathrm{~kW}$. A maior capacidade de colheita foi $6,56 \mathrm{t} \mathrm{h}^{-1}$ e o consumo específico de energia apresentou valor mínimo de 2,46 $\mathrm{kWh} \mathrm{t}^{-1}$.
\end{abstract}

Palavras-chave: colheita, máquina de arrasto, consumo de energia

\section{Power requirement for driving an axial flow bean harvester}

\begin{abstract}
The objective of this work was to find the power requirement for operating an axial flow bean harvester. Experimental tests were performed, the torque and angular velocity in the power take-off (PTO), the drawbar force, the machine speed and harvesting capacity were measured. To analyze the effect of the variables on the power needed, regression analysis were done. The drawbar power for the maximum grain bin capacity was $7.90 \mathrm{~kW}$. The maximum PTO power to operate the machine was found to be $45.28 \mathrm{~kW}$. The maximum harvesting capacity was $6.56 \mathrm{t} \mathrm{h}^{-1}$. The minimum specific energy consumption was $2.46 \mathrm{kWh} \mathrm{t}^{-1}$.
\end{abstract}

Key words: harvesting, pull-type machine, energy consumption

\section{INTRODUÇÃO}

A agricultura moderna exige qualidade e produtividade nas operações que a compõem, em que a competitividade tem levado as empresas a reduzir custos e colocar produtos de alta qualidade no mercado consumidor. Esta realidade representa desafios, uma vez que, além de ser uma atividade complexa, muitas vezes a agricultura depende de aspectos climáticos.

Com a utilização de grandes áreas de cultivo, além da escassez de trabalhadores no meio rural e demanda de mãode-obra flutuante durante os processos agrícolas, a cultura do feijão tem gerado uma crescente necessidade da mecanização de todas as etapas da produção. Dentre as etapas do ciclo operacional de uma cultura, a colheita normalmente se destaca, em virtude das dificuldades e dos altos custos envolvidos, seja ela realizada de forma manual ou mecanizada.
$\mathrm{Na}$ cultura do feijão, a colheita pode ser feita manual, mecanicamente ou por uma combinação de ambas (Silva \& Queiroz, 1998). A colheita utilizando a combinação manual e mecânica, é realizada com pelo menos três operações de campo, em um período de 2 a 12 dias, visto que consiste em arrancar as plantas inteiras, quando estas se encontram quase desprovidas de folhas e os grãos com baixo teor de umidade. Com as plantas arrancadas, formam-se leiras que permanecem na lavoura para completar o processo de secagem e homogeneização natural (Conto et al., 1980) e, por fim, uma máquina colhedora de grãos, convencional ou específica para feijão, recolhe o produto e separa os grãos do resto da planta (Smith, 1986).

A utilização adequada de máquinas e equipamentos agrícolas tem várias vantagens, como melhorar o rendimento operacional, facilitar o trabalho do homem do campo, possibilitar a expansão do cultivo e atender ao cronograma de atividades no tempo 
disponível (Delafosse, 1986). Um problema atualmente encontrado é que, antes do uso pleno e intensivo do equipamento, são feitas mudanças sem mesmo se identificar os sistemas que demandam por melhorias.

Kim \& Gregory (1989) citam a carência de trabalhos publicados abordando funções matemáticas que descrevam o comportamento do consumo de energia demandado por máquina de colheita. Rotz \& Muhtar (1992) reforçam essa afirmativa, relatando que as informações sobre a exigência de potência são muito limitadas, sendo que a maioria das informações encontradas na literatura se refere à perda de matéria e à qualidade do produto colhido; entretanto, desde a última década o feijão deixou de ser uma cultura de subsistência, tornando-se uma cultura tecnificada (Santos \& Braga, 1998) surgindo, assim, a necessidade de novos trabalhos, principalmente explorando os efeitos da taxa de alimentação, da velocidade periférica do cilindro trilhador e do estado das condições da cultura na exigência de energia de colhedoras.

Segundo Mantilla \& Ramos (1998) os principais parâmetros que afetam o consumo de energia durante o processo de colheita mecânica, são a velocidade periférica, o diâmetro e o momento de inércia do cilindro trilhador, a abertura entre cilindro e côncavo, o tipo e as dimensões do côncavo, além das características físico-mecânicas da cultura. A taxa de alimentação é um outro parâmetro que influencia, significativamente, o consumo de energia de máquinas de colheita (Arnold \& Lake, 1964; Dodds, 1968; Bjork, 1988; Kim \& Gregory, 1989).

Devido à necessidade de se conhecer o desempenho das máquinas destinadas à colheita do feijão e de se obter dados relativos à necessidade de potência das máquinas agrícolas para realização da seleção do trator adequado para sua operação, este trabalho foi desenvolvido com o objetivo de se avaliar a demanda de potência e a energia requerida por uma colhedora em campo.

\section{MATERIAL E MÉTODOS}

O trabalho de preparação da máquina colhedora para realização dos testes experimentais, foi conduzido no Laboratório de Mecanização Agrícola do Departamento de Engenharia Agrícola da Universidade Federal de Viçosa e nas empresas MIAC, COTRAME e AEMCO, todas pertencentes às Indústrias Reunidas Colombo Ltda. Os testes experimentais foram realizados no Campo Experimental da Embrapa Milho e Sorgo.

O produto utilizado nos ensaios foi o feijão (Phaseolus vulgaris L.) cultivar Carioca, sendo a máquina avaliada uma colhedora de arrasto modelo "Double Master" (Figura 1) com sistema de trilha em fluxo axial, a qual apresentava $2,45 \mathrm{~m}$ de largura total, 2,12 $\mathrm{m}$ de bitola, 3,25 $\mathrm{m}$ de altura, 6,30 $\mathrm{m}$ de comprimento, $3406 \mathrm{~kg}$ de massa total, $0,543 \mathrm{~m}$ de diâmetro e 1,90 $\mathrm{m}$ de largura do cilindro trilhador, $2,70 \mathrm{~m}$ de comprimento do côncavo e, segundo o fabricante, $2400 \mathrm{~kg}$ de capacidade do tanque graneleiro, $1250 \mathrm{~kg} \mathrm{~h}^{-1}$ de capacidade de colheita, sendo exigidos $88,0 \mathrm{~kW}$ para seu acionamento. A máquina foi tracionada e acionada por um trator Massey-Ferguson, Modelo MF 620 Hydrotronic, com potência nominal de $82 \mathrm{~kW}$ e $6000 \mathrm{~kg}$ de massa total. A colhedora foi equipada com o pneu R1 12,4 - 24 e o trator com pneu dianteiro R1 14,9 - 24 e traseiro R1 18,4 - 34.

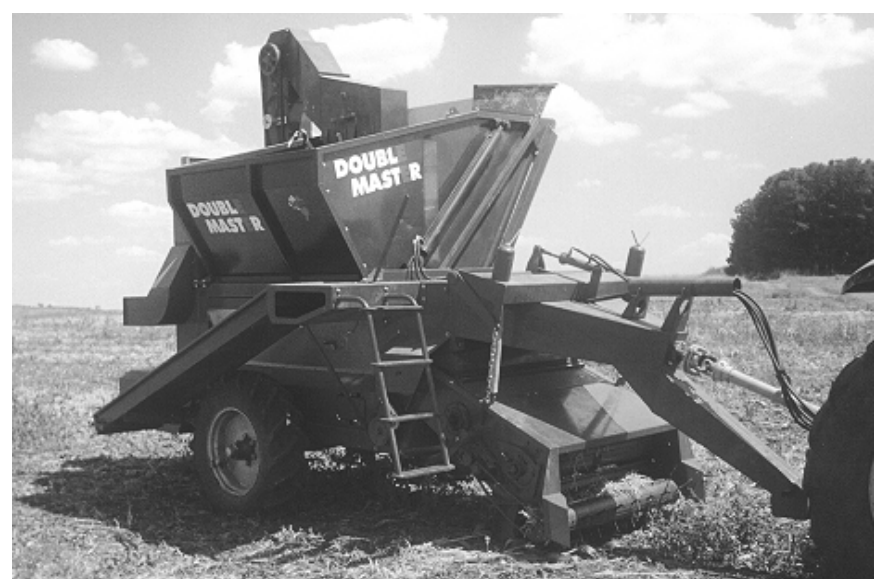

Figura 1. Colhedora modelo "Double Master"

As variáveis investigadas nos ensaios foram taxa de alimentação da máquina, obtida pela variação do número de linhas de feijão na leira (4, 7 e 10 linhas) e pela velocidade de trabalho da máquina $\left(4,7\right.$ e $\left.10 \mathrm{~km} \mathrm{~h}^{-1}\right)$, e rotação do cilindro trilhador, trabalhando-se com 420 e 540 rotações min $^{-1}$, obtidas variando-se a rotação do motor do trator. A abertura entre cilindro e côncavo foi de $20 \mathrm{~mm}$. Montou-se um experimento em esquema fatorial $3 \times 3 \times 2$, com três constituições de leira, três velocidades de deslocamento e duas rotações do cilindro trilhador, instalado segundo o delineamento inteiramente casualizado, com duas repetições. Os dados obtidos foram submetidos à análise de variância e à metodologia de superfície de resposta, e os modelos escolhidos com base na significância dos coeficientes de regressão, utilizando-se o teste t a 5\% e o coeficiente de determinação, enquanto os dados obtidos foram analisados estatisticamente, utilizando-se o programa computacional SAEG, versão 8 .

Foram determinados o torque e a rotação na tomada de potência (TDP), a força na barra de tração do trator, a velocidade de deslocamento da máquina, a massa de grãos colhidos e o tempo necessário para colhê-la.

Nas avaliações, foram consideradas duas faixas de teores de umidade de colheita, sendo uma de $10,65 \pm 0,25$ e outra de $14,10 \pm 0,81 \%$ b.u. Buscando-se minimizar o desvio entre os valores de teor de umidade de colheita, os testes foram conduzidos em duas áreas irrigadas por pivô central.

O torque na TDP do trator foi monitorado utilizando-se um torquímetro marca Omega, com capacidade máxima de $120 \mathrm{Nm}$, e que utiliza "strain gages" como princípio de funcionamento. $\mathrm{O}$ torquímetro foi instalado entre a árvore do cilindro trilhador e seu eixo cardã secundário, de acionamento (Figura 2A) que recebe o movimento da TDP; juntamente com o torque, a rotação na TDP foi determinada utilizando-se um sensor de pulso colocado a aproximadamente $4 \mathrm{~mm}$ de distância do ponto de excitação (Figura 2B). A excitação do sensor foi realizada por um dispositivo metálico colocado no eixo cardã, que é acionado pela TDP. A potência para acionamento dos órgãos internos da colhedora foi determinada utilizando-se o torque e a velocidade angular na TDP do trator, as leituras do torque foram feitas em um mostrador digital da marca Omega e as da rotação em um multímetro digital marca Tektronix, modelo "TEK DMM252". 
A.

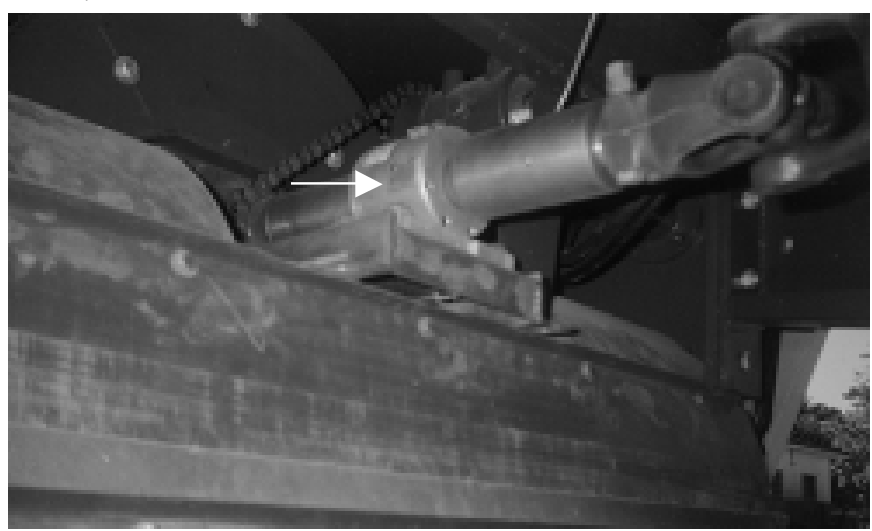

B.

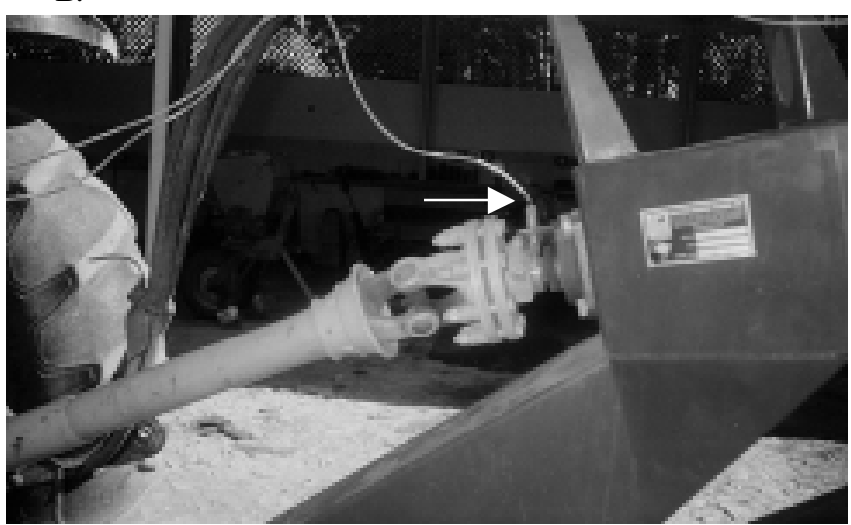

Figura 2. Local de instalação do torquímetro (A) e do sensor de pulso (B) na colhedora

Para se determinar a potência na barra de tração do trator, mensuraram-se a força na barra e a velocidade de deslocamento da máquina. Para obtenção da força na barra de tração, usou-se uma célula de carga da marca Omega, em forma de "S", com capacidade máxima de $50 \mathrm{kN}$. Esta célula de carga deveria trabalhar sem sofrer flexão e por isso se construiu um anteparo, que substituiu a barra de tração do trator (Figura 3). Desta maneira a célula de carga ficou fixa, sujeita apenas à força de tração. A Figura 4 apresenta o detalhe do projeto do anteparo de colocação da célula de carga.

Para se vencer a resistência ao rolamento, imposta pelo solo, torna-se necessária uma força adicional, que deve ser

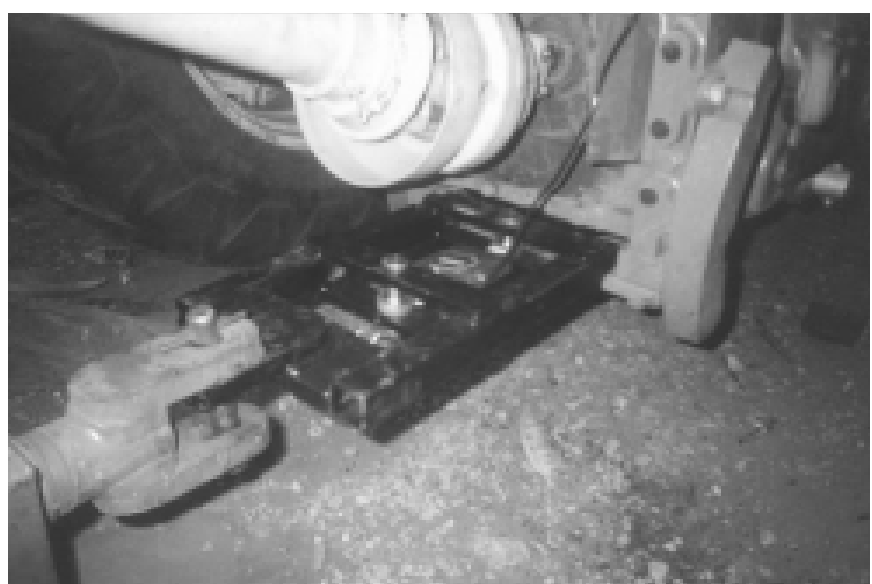

Figura 3. Anteparo e célula de carga colocados entre trator e máquina

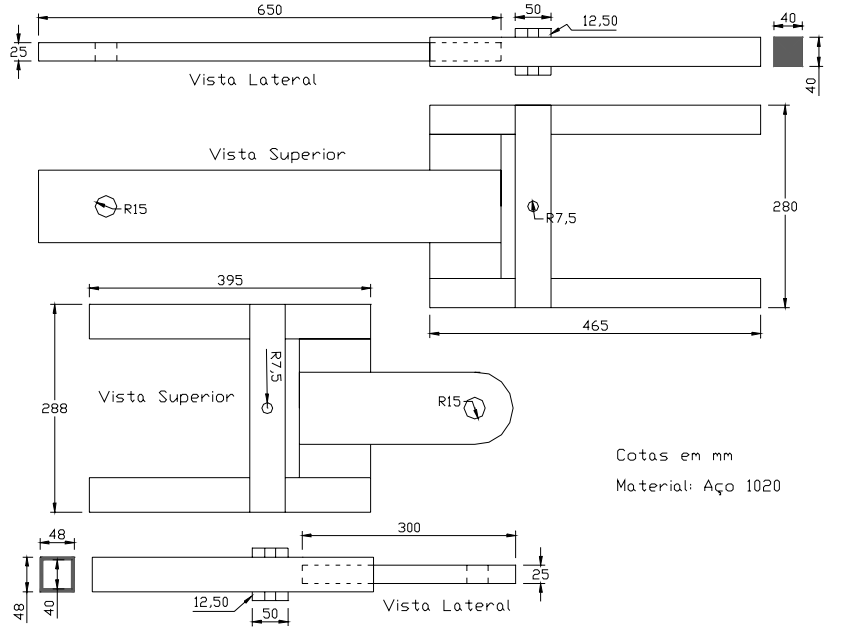

Figura 4. Esboço do projeto do anteparo

incluída no cálculo da potência requerida para tração da máquina e que pode ser determinada por meio do coeficiente de resistência ao rolamento, obtido da relação entre a resistência ao rolamento, que foi considerada igual à força de tração, e a carga dinâmica sobre o rodado (ASAE, 1990) conforme se segue.

$$
\mathrm{C}_{\mathrm{r}}=\frac{\mathrm{R}_{\mathrm{r}}}{\mathrm{W}_{\mathrm{d}}}
$$

em que:

$\mathrm{C}_{\mathrm{r}}$ - coeficiente de resistência ao rolamento

$\mathrm{R}_{\mathrm{r}} \quad$ - resistência ao rolamento, $\mathrm{kN}$

$\mathrm{W}_{\mathrm{d}}$ - carga dinâmica sobre o rodado, $\mathrm{kN}$

De acordo com a Standard D497 (ASAE, 1990) a potência exigida pelos órgãos rotativos de uma colhedora de grãos, com teor de umidade de colheita de $20 \%$, pode ser estimada pela seguinte expressão:

$$
P=7,5+7,5 q
$$

em que:

$\mathrm{P}$ - potência exigida pelos órgãos rotativos, $\mathrm{kW}$

q - taxa de alimentação da máquina, $\mathrm{kg} \mathrm{s}^{-1}$

A velocidade de trabalho da máquina foi determinada tomando-se por base o tempo gasto para a mesma percorrer, em operação, uma distância de $100 \mathrm{~m}$.

Para a determinação da capacidade de colheita que, segundo Ripoli (1996) é entendida como a quantidade de trabalho que um conjunto de máquinas, ou uma colhedora isoladamente, é capaz de executar na unidade de tempo, a máquina foi colocada para colher numa distância conhecida, cronometrando-se o tempo gasto para que a mesma percorresse essa distância e, em seguida, o produto colhido foi pesado. A capacidade de colheita foi obtida da relação entre a massa de grãos colhidos e o tempo gasto no percurso, conforme observado na Eq. (3). Para garantir que um teste não influenciasse o próximo, a máquina foi totalmente limpa de grãos e palhada ao final de cada teste. 


$$
\mathrm{C}_{\mathrm{c}}=3,6 \frac{\mathrm{m}_{\mathrm{g}}}{\mathrm{t}}
$$

em que:

$$
\begin{array}{ll}
\mathrm{C}_{\mathrm{c}} & \text { - capacidade de colheita, } \mathrm{t} \mathrm{h}^{-1} \\
\mathrm{~m}_{\mathrm{g}} & \text { - massa de grãos colhidos, } \mathrm{kg} \\
\mathrm{t} & \text { - tempo gasto para colher } \mathrm{m}_{\mathrm{g}}, \mathrm{s}
\end{array}
$$

O consumo específico de energia foi determinado pela relação entre a potência exigida na operação e a capacidade de colheita, conforme se segue.

$$
\mathrm{C}_{\mathrm{e}}=\frac{\mathrm{P}}{\mathrm{C}_{\mathrm{c}}}
$$

em que:

$\mathrm{C}_{\mathrm{e}} \quad$ - consumo específico de energia, $\mathrm{kWh} \mathrm{t}^{-1}$

\section{RESULTADOS E DISCUSSÃO}

$\mathrm{Na}$ Figura 5A tem-se os resultados médios das forças e potências necessárias para tração, observadas em função do carregamento de grãos no tanque graneleiro da colhedora. Os dados de força e potência de tração apresentaram comportamento quadrático de seus valores. Este comportamento foi devido à interação rodado-solo pois, quanto maior a carga sobre o pneu, mais este e o solo se deformam, uma vez que a pressão de

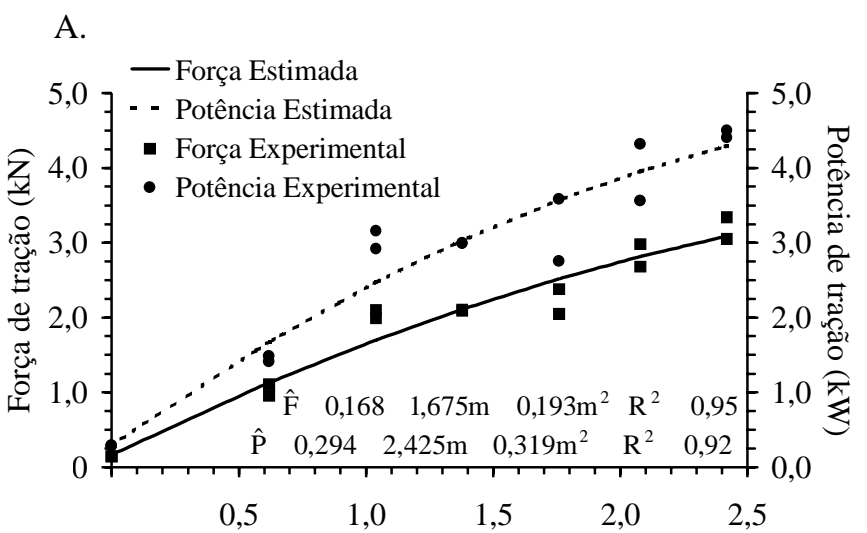

B.

Massa de grãos no graneleiro $(\mathrm{t})$

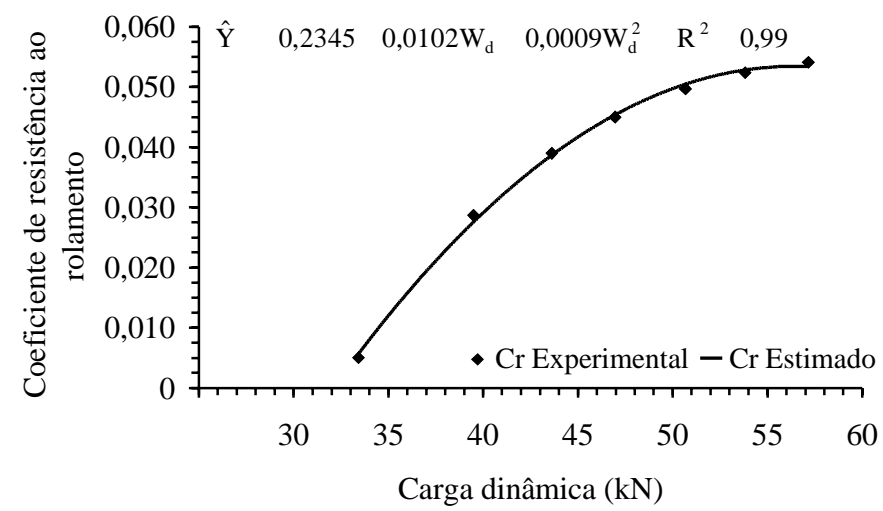

Figura 5. Força e potência de tração em função da massa de grãos contida no tanque graneleiro da máquina (A) e coeficiente de resistência ao rolamento $(\mathrm{Cr})$ em função da carga dinâmica (B) insuflagem do pneu, recomendada pelo fabricante, foi mantida constante.

Analisando-se a curva de força de tração, Figura 5A, verifica-se que o maior valor ocorreu no ponto de máxima capacidade de enchimento do tanque graneleiro da colhedora, que foi de $2420 \mathrm{~kg}$ e exigiu uma força na barra de tração de 3,09 kN para arrastá-la totalmente carregada, ou seja, para vencer a resistência ao rolamento. Trabalhando com uma velocidade de $5,40 \pm 0,49 \mathrm{~km} \mathrm{~h}^{-1}$, a colhedora demandou uma potência na barra de tração de $4,29 \mathrm{~kW}$.

A potência de tração equivalente no motor do trator foi determinada utilizando-se uma eficiência tratória de $65 \%$, uma relação entre a potência no eixo motriz e a potência na TDP de 0,96 e uma eficiência de transmissão do motor para a TDP de 87\%, conforme Standard EP496.2 (ASAE, 2000); assim, com carregamento máximo do tanque graneleiro, a potência exigida no motor do trator para tracionar a colhedora foi de 7,90 kW.

Os pontos de interseção das curvas com o eixo das ordenadas, representam a força e a potência necessária para arrastar a máquina com o tanque graneleiro vazio, ou seja, tendo influência apenas do peso da colhedora, que foi de $0,334 \mathrm{kN}$ (Figura 5A).

$\mathrm{Na}$ Figura 5B observa-se que os dados do coeficiente de resistência ao rolamento, em função da carga dinâmica, apresentaram comportamento quadrático, mostrando que o aumento da massa sobre o eixo da máquina exige uma força adicional para vencer a resistência imposta pelo solo ao rolamento do rodado.

Para se estudar o comportamento da potência na TDP do trator em função do número de linhas de feijão na leira, da velocidade de deslocamento e rotação do cilindro trilhador da máquina, foram feitos cortes nos modelos de superfície de resposta ajustados, como apresentado nas Figuras 6 e 7.
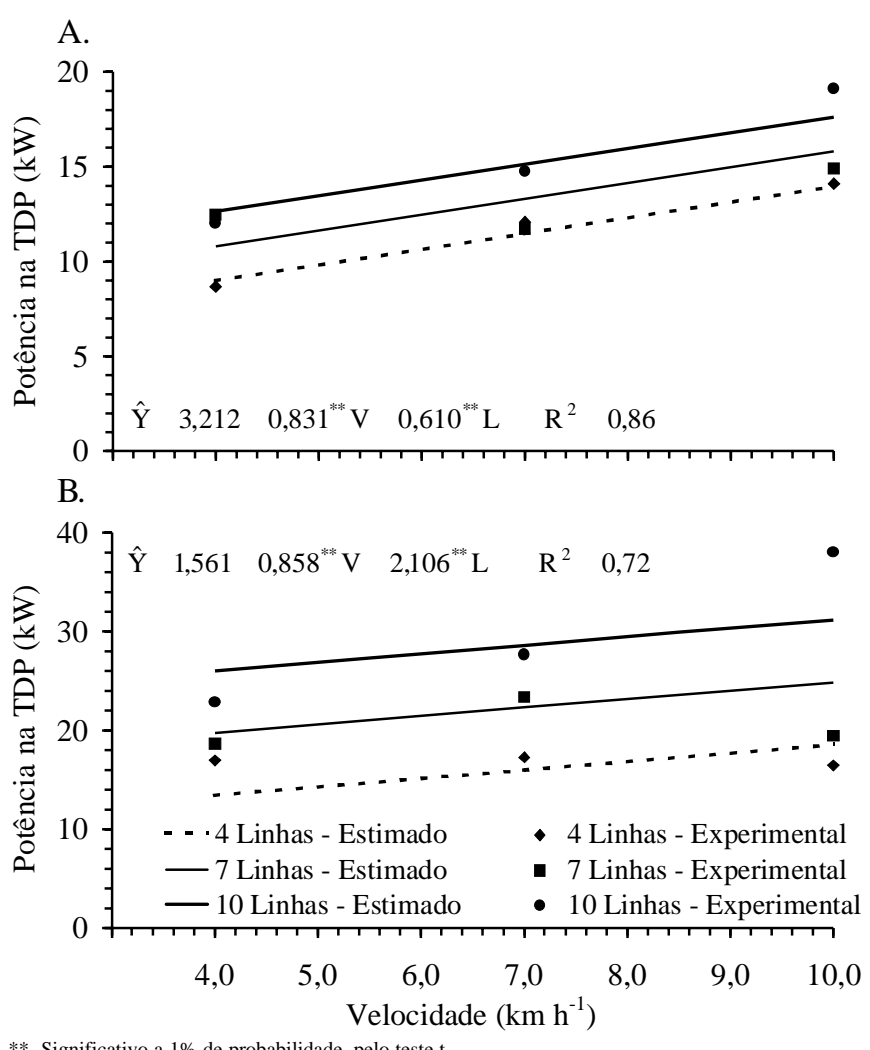

Figura 6. Estimativa da potência na TDP, em função da velocidade de deslocamento da máquina, para as respectivas constituições de leira, com o cilindro trilhador a 420 (A) e 540 rotações $\min ^{-1}(\mathrm{~B})$ e teor médio de umidade de 10,65\% 

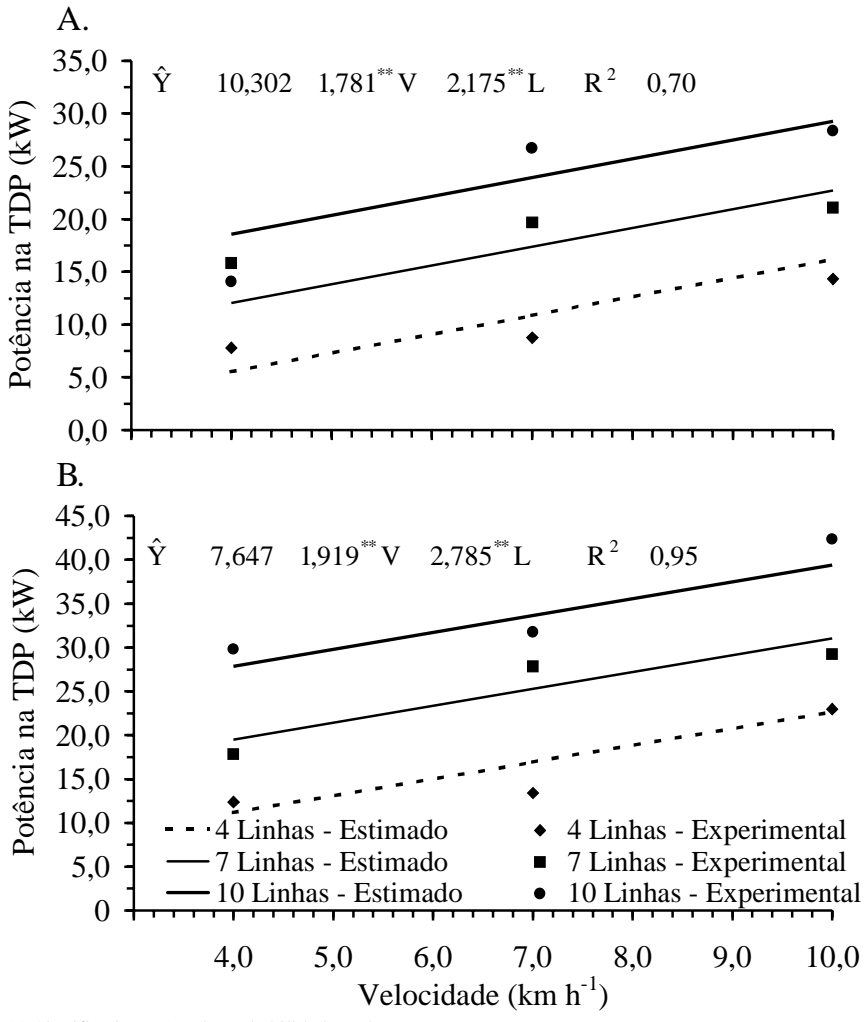

** Significativo a $1 \%$ de probabilidade, pelo teste $\mathrm{t}$

Figura 7. Estimativa da potência na TDP, em função da velocidade de deslocamento da máquina, para as respectivas constituições de leira, com o cilindro trilhador a 420 (A) e 540 rotações $\min ^{-1}(\mathrm{~B})$ e teor médio de umidade de $14,10 \%$

A potência na TDP aumentou com o incremento da velocidade e do número de linhas na leira. A demanda de potência na rotação do cilindro trilhador de 540 rotações $\min ^{-1}$ foi superior à demanda na rotação de 420 . Esses comportamentos foram observados nos dois teores de umidade. Resultado semelhante foi obtido por Dodds (1968) que demonstrou que a demanda de potência foi função linear da taxa de alimentação da colhedora.

Os testes realizados com teor de umidade de $14,10 \%$ apresentaram maiores valores de potência na TDP que aqueles realizados com teor de umidade de $10,65 \%$, provocado pela diferença entre as produtividades e os teores de umidade. A produtividade média determinada nos testes com teor de umidade de $10,65 \%$ foi $2238,20 \mathrm{~kg} \mathrm{ha}^{-1}$, enquanto com teor de umidade de $14,10 \%$ foi $2532,35 \mathrm{~kg} \mathrm{ha}^{-1}$. A produtividade tem influência direta na taxa de alimentação da máquina e o teor de umidade aumenta a necessidade de energia para ocorrência da trilha.

As maiores potências observadas para acionamento dos órgãos internos da máquina foram determinadas nas condições próximas ao limite de processamento da mesma, que foi de aproximadamente $5,00 \mathrm{~kg} \mathrm{~s}^{-1}$. A maior potência na TDP exigida foi 31,20 e 39,39 kW, nos testes com teor de umidade de 10,65 e $14,10 \%$, respectivamente. As potências máximas equivalentes no motor do trator, assumindo-se uma eficiência de transmissão do motor para a TDP de $87 \%$ (ASAE, 2000) foram de 35,86 e $45,28 \mathrm{~kW}$ na colheita dos grãos com teor de umidade de $10,65 \mathrm{e}$ $14,10 \%$, respectivamente. Uma colhedora combinada para soja, com sistema convencional de trilha e trabalhando a uma mesma taxa de alimentação, demandaria em torno de $39,83 \mathrm{~kW}$ de potência na TDP (Eq. 2). Por outro lado, a potência total equivalente no motor do trator para se trabalhar com a máquina alimentada com 4,31 $\mathrm{kg} \mathrm{s}^{-1}$ de matéria bruta - obtida da combinação da leira de 10 linhas e velocidade de $10 \mathrm{~km} \mathrm{~h}^{-1}$ - usando-se 540 rotações $\min ^{-1}$ na TDP, teor médio de umidade do produto de $14,10 \%$ e com carregamento máximo de enchimento do tanque graneleiro, foi de $53,18 \mathrm{~kW}$.

Analisando-se a relação entre a potência de acionamento dos órgãos internos e a potência total da colhedora, verifica-se que $14,86 \%$ da potência exigida pela máquina são usados na tração. Burrough (1954), Arnold \& Lake (1964) e Kepner (1982) revelaram, por meio de dados experimentais, que até $80 \%$ da energia requerida por colhedoras são consumidos no sistema de trilha.

Na Figura 8 são apresentados os dados de potência na TDP do trator, em função da taxa de alimentação da colhedora. Os dados de potência na TDP apresentaram comportamento linear crescente, em função da taxa de alimentação da colhedora. Comparando-se os valores de potência na TDP obtidos experimentalmente, com aqueles estimados por meio da Eq. (2), verificou-se um erro relativo médio de 33,73 e 23,83\% para o teor de umidade de colheita de 10,65 e 14,10\%, respectivamente. Esta diferença pode ser atribuída, em parte, à diferença no teor de umidade, pois a Eq. (2) foi proposta para produtos com teor de umidade médio de $20 \%$. Os valores de potência na TDP, para acionamento da máquina trabalhando vazia, foram 8,21 e 13,09 kW, para as rotações do cilindro trilhador de 420 e 540 rotações $\min ^{-1}$, respectivamente. A potência na TDP média,

A.

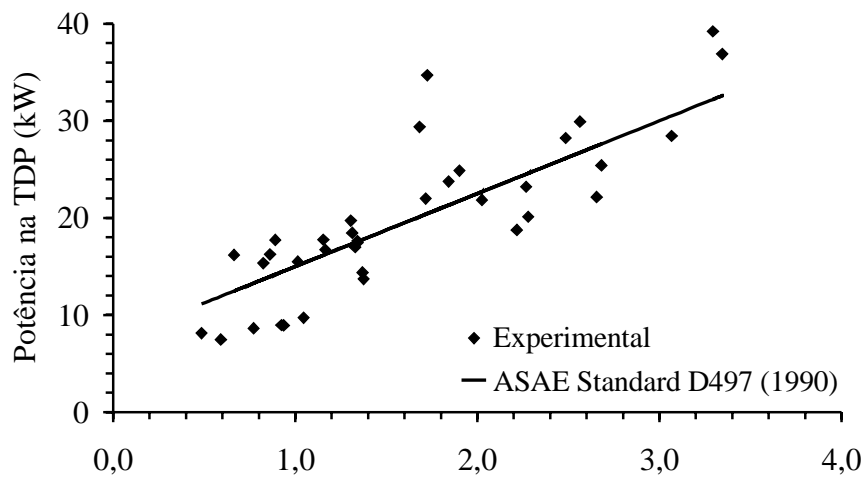

B.

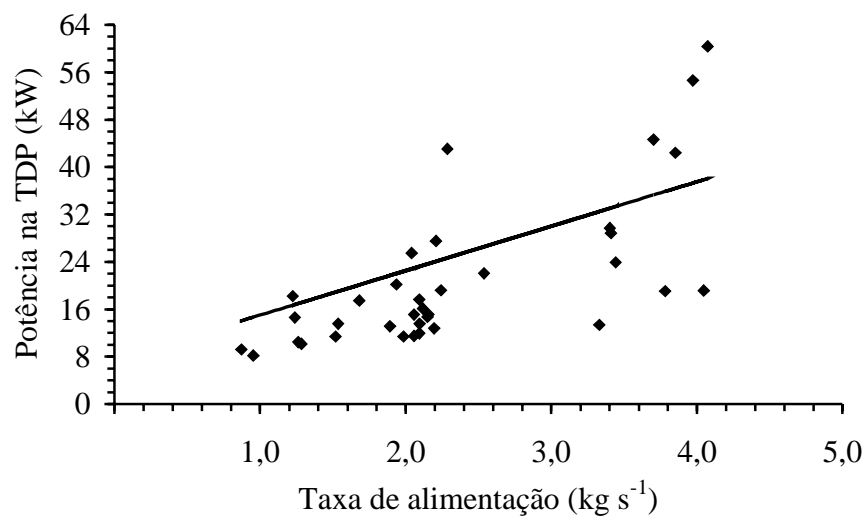

Figura 8. Estimativa da potência na TDP, em função da taxa de alimentação da máquina, com teor médio de umidade de colheita de 10,65 (A) e 14,10\% (B) 
obtida no limite de embuchamento da colhedora, atingiu o valor de $57,46 \mathrm{~kW}$ para uma taxa de alimentação de palhada de $1,955 \mathrm{~kg} \mathrm{~s}^{-1}$.

Para se estudar o comportamento da capacidade de colheita em função do número de linhas de feijão na leira, da velocidade de deslocamento e rotação do cilindro trilhador da máquina, foram feitos cortes nos modelos de superfície de resposta ajustados, conforme apresentado nas Figuras 9 e 10.

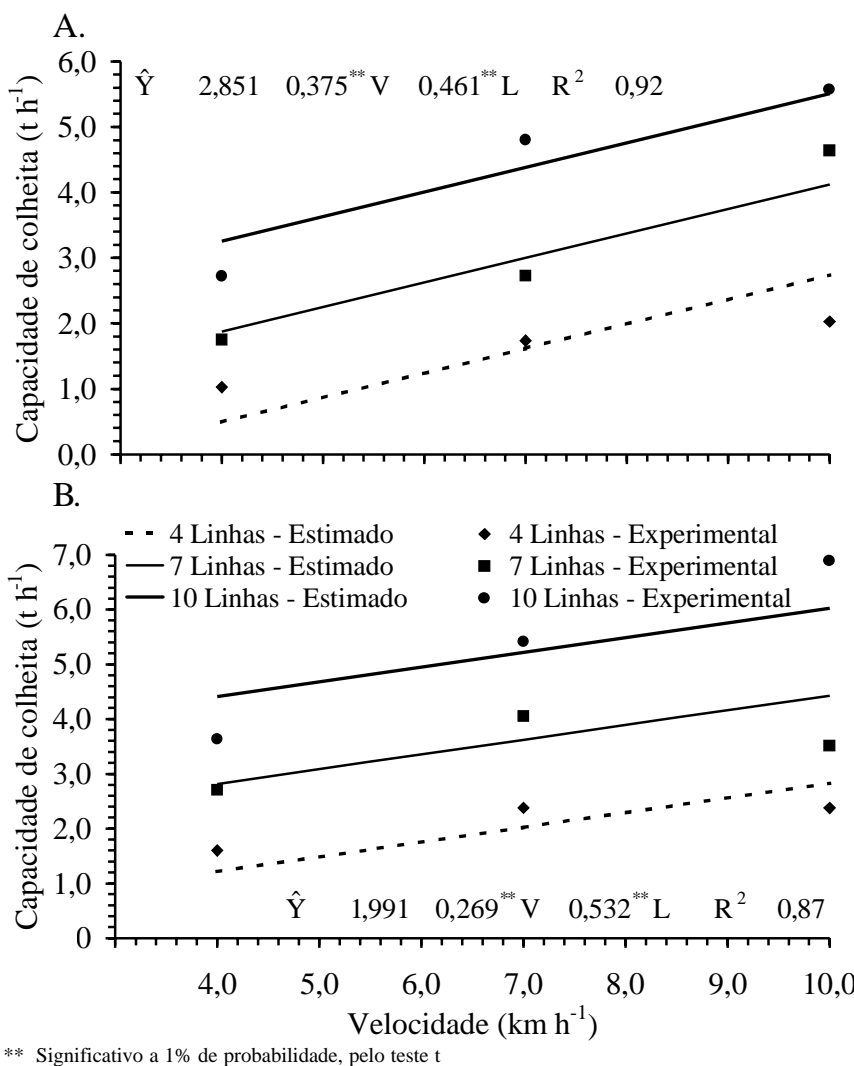

Figura 9. Estimativa da capacidade de colheita, em função da velocidade de deslocamento da máquina, para as respectivas constituições de leira, com o cilindro trilhador a 420 (A) e 540 rotações $\mathrm{min}^{-1}(\mathrm{~B})$ e teor médio de umidade de $10,65 \%$

Os dados de capacidade de colheita em função da velocidade de deslocamento da máquina, do número de linhas na leira e da rotação do cilindro trilhador, evidenciaram aumento linear de seus valores. Por sua vez, as leiras constituídas de 10 linhas apresentaram maiores valores de capacidade de colheita que as demais, acontecendo o mesmo para a velocidade de $10,0 \mathrm{~km} \mathrm{~h}^{-1}$ com o cilindro trilhador a 540 rotações $\mathrm{min}^{-1}$. Os melhores resultados da capacidade de colheita foram observados nos testes com teor de umidade de $14,10 \%$, com maior valor de $6,56 \mathrm{t} \mathrm{h}^{-1}$, enquanto que com teor de umidade de $10,65 \%$ observou-se maior valor de $6,02 \mathrm{t} \mathrm{h}^{-1}$. A diferença entre esses valores está associada à variação de produtividade entre os testes com teor de umidade de 10,65 e 14,10\% (Figuras 9 e 10).

A rotação do cilindro trilhador da máquina influenciou o aumento da capacidade de colheita, porque esta foi incrementada variando-se a rotação do motor do trator. Observou-se que, em campo e quando se trabalhava em baixa rotação na TDP, ao aumentar a taxa de alimentação da máquina ocorria um ligeiro decréscimo na velocidade de deslocamento para compensar a maior exigência de torque do cilindro trilhador.

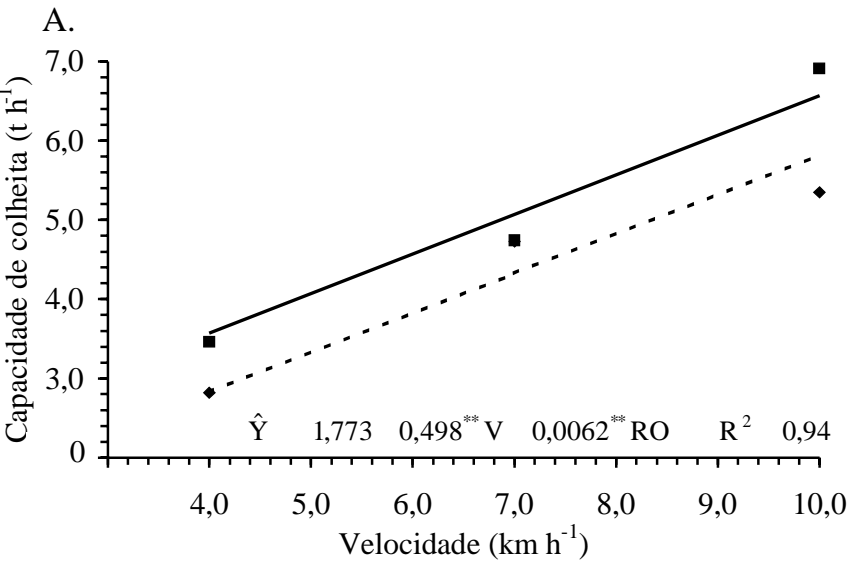

B.

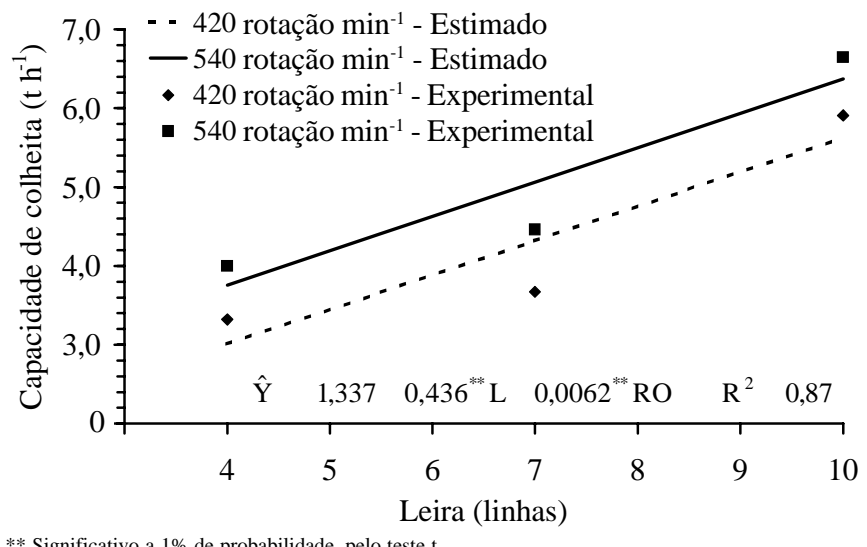

** Significativo a $1 \%$ de probabilidade, pelo teste t

Figura 10. Estimativa da capacidade de colheita, em função da velocidade de deslocamento da máquina (A) e constituição de leira (B) para as respectivas rotações do cilindro trilhador, com teor médio de umidade de $14,10 \%$

Segundo Skromme (1977) as colhedoras com sistema de trilha em fluxo axial apresentam maior capacidade de colheita e reduzem os índices de danos mecânicos, em relação às colhedoras com sistema de trilha com fluxo radial.

Para se estudar o comportamento do consumo específico de energia em função do número de linhas de feijão na leira, da velocidade de deslocamento e rotação do cilindro trilhador da máquina, realizaram-se cortes nos modelos de superfície de resposta ajustados, conforme apresentado nas Figuras 11 e 12.

Analisando-se o comportamento do consumo específico de energia em função da velocidade de deslocamento da máquina e se fixando o número de linhas na leira, pode-se verificar que os dados apresentaram resposta quadrática de seus valores, exceto quando o cilindro trilhador funciona com 540 rotações $\min ^{-1}$ e teor de umidade de $14,10 \%$, que apresentou tendência linear com a velocidade de deslocamento da máquina. Os dados referentes às rotações evidenciaram comportamento crescente dos valores do consumo específico de energia. Resultados semelhantes foram observados por Arnold \& Lake (1964) que verificaram que o consumo de energia varia com o quadrado da taxa de alimentação.

Os menores valores de consumo específico de energia foram observados para o teor de umidade de $14,10 \%$, com valores de 2,46 e $3,98 \mathrm{kWh} \mathrm{t}^{-1}$ para o cilindro trilhador funcionando a 420 e 540 rotações $\min ^{-1}$ e velocidades de 7,9 e $10,0 \mathrm{~km} \mathrm{~h}^{-1}$, respectivamente; no entanto, para o teor de umidade de $10,65 \%$ 
A.

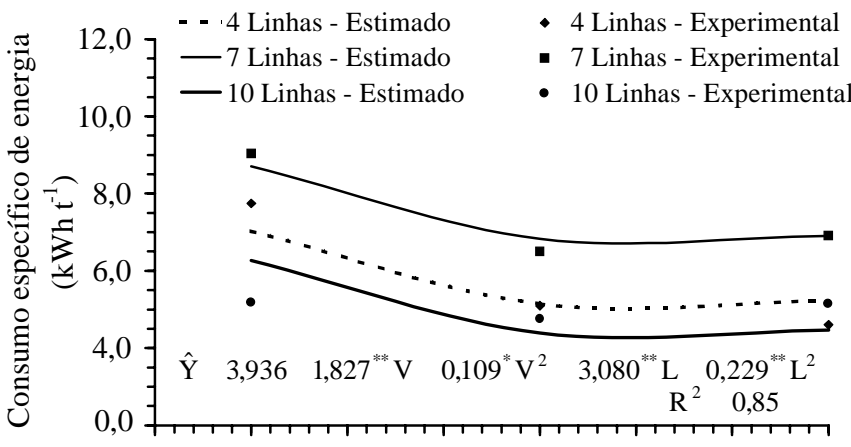

B.

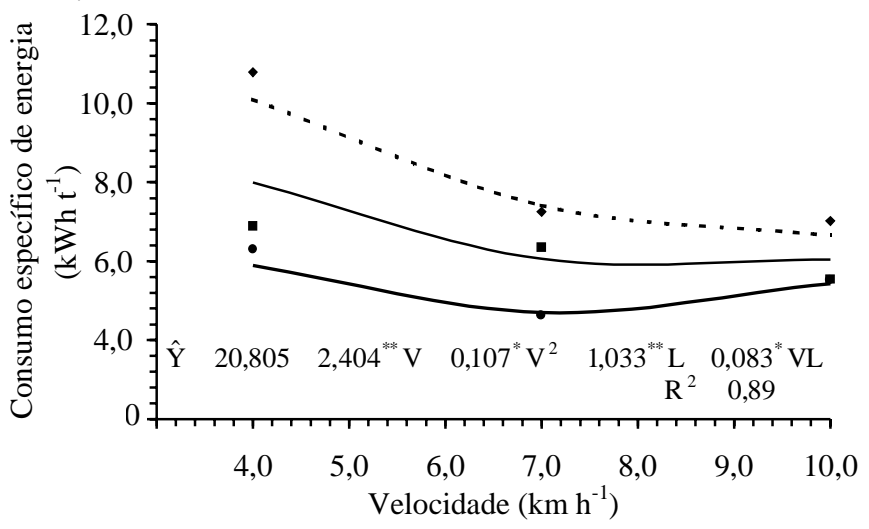

** e * Significativo a 1 e $5 \%$ de probabilidade, respectivamente, pelo teste t

Figura 11. Estimativa do consumo específico de energia, em função da velocidade de deslocamento da máquina, para as respectivas constituições de leira, com o cilindro trilhador a 420 (A) e 540 rotações $\min ^{-1}$ (B) e teor médio de umidade de $10,65 \%$

foram determinados, nas mesmas rotações, valores de 4,18 e $4,67 \mathrm{kWh} \mathrm{t}^{-1}$ para velocidades de 8,4 e 7,4 $\mathrm{km} \mathrm{h}^{-1}$, respectivamente.

$\mathrm{O}$ cilindro trilhador funcionando com 540 rotações $\mathrm{min}^{-1}$ apresentou maiores valores de consumo específico de energia, o que pode ser explicado pelo fato das perdas de potência serem maiores quanto maior for sua rotação.

\section{CONCLUSÕES}

1. A potência necessária para tracionar a máquina e o coeficiente de resistência ao rolamento mostraram-se muito influenciados pelo carregamento de grãos no tanque graneleiro da colhedora.

2. O teor de umidade de $14,10 \%, 540$ rotações $\min ^{-1}$ no cilindro trilhador e o as maiores taxas de alimentação exigiram maior potência de acionamento dos órgãos internos da colhedora.

3. A potência total exigida no motor do trator para trabalhar com a máquina foi inferior a recomendada pelo fabricante, para as condições testadas.

4. As maiores capacidades de colheita foram observadas nos testes com $14,10 \%$ de teor de umidade, 540 rotações min $^{-1}$ e maior taxa de alimentação.

5. A velocidade média de deslocamento da colhedora de $8,43 \mathrm{~km} \mathrm{~h}^{-1}$, o teor de umidade de colheita de $14,10 \%$ e o cilindro trilhador trabalhando com 420 rotações $\mathrm{min}^{-1}$ proporcionaram menor consumo específico de energia.
A.

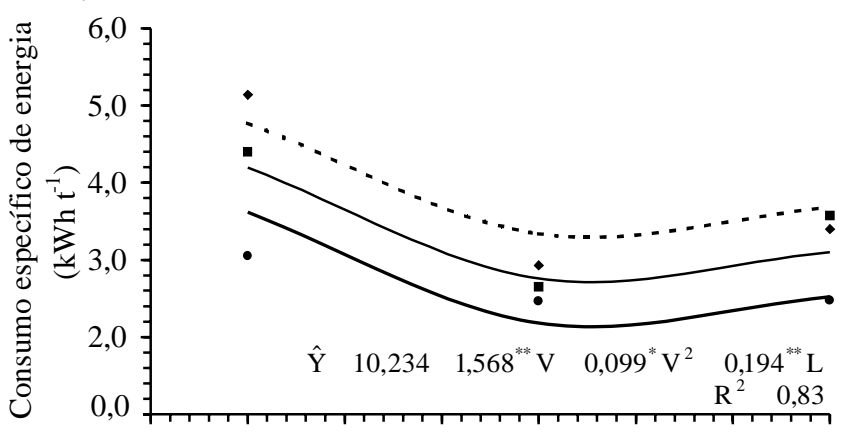

B.

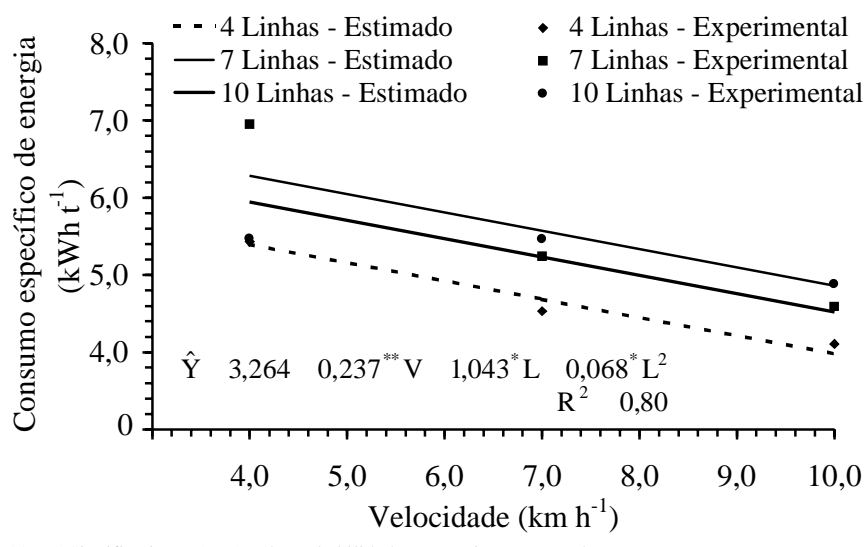

** e * Significativo a 1 e $5 \%$ de probabilidade, respectivamente, pelo teste t

Figura 12. Estimativa do consumo específico de energia, em função da velocidade de deslocamento da máquina, para as respectivas constituições de leira, com o cilindro trilhador a 420 (A) e 540 rotações $\min ^{-1}$ (B) e teor médio de umidade de $14,10 \%$

\section{AGRADECIMENTOS}

Ao CNPq - Conselho Nacional de Desenvolvimento Científico e Tecnológico.

À FAPEMIG - Fundação de Amparo à Pesquisa do Estado de Minas Gerais.

Às Indústrias Reunidas Colombo Ltda.

\section{LITERATURA CITADA}

Arnold, R.E.; Lake, J.R. Experiments with rasp bar threshing drums. III Power requirement. Journal of Agricultural Engineering Research, Silsoe, v.9, p.348-355. 1964.

ASAE - American Society of Agricultural Engineers. Standards D497. St. Joseph, Michigan, 1990. p.285-291.

ASAE - American Society of Agricultural Engineers. Standards EP496.2. St. Joseph, Michigan, 2000. p.344-349.

Bjork, A. Power requirement for threshing and separation in a rotary combine. ASAE, St. Joseph, 1988. 14p. Paper No. PNR 88-204

Burrough, D.E. Power requirements of combine drives. Agricultural Engineering, Silsoe, v.35, n.1, p.15-18, 1954.

Conto, A.J.; Vieira, E.H.N.; Oliveira, E.T.; Castro, T.A.P. Aspecto técnico e econômico da colheita mecânica e manual do feijão (Phaseolus vulgaris L.). Goiânia: EMBRAPA-CNPAF. 1980. 18p. Circular Técnica 2 
Delafosse, R.M. Máquinas sembradoras de grano grueso. Santiago: Oficina Regional de la FAO para América Latina y el Caribe. 1986. 48p.

Dodds, M.E. Power requirements of a self-propelled combine. Canadian Agricultural Engineering, Saskatoon, v.10, n.2, p.74-76, 90, 1968.

Kepner, R.A.; Bainer, R.; Barger, E.L. Principles of farm machinery. 3 ed. Westport: AVI Publishing Company. 1982. p.392-431.

Kim, S.H.; Gregory, J.M. Power requirement model for combine cylinders. ASAE, St. Joseph, 1989. 10p. Paper No. 89-1592

Mantilla, E.N.; Ramos, J.N. Metodología de cálculo de órganos trilladores del tipo cilindro cóncavo. Revista Ciencias Técnicas Agropecuarias. La Habana, v.7, n.2., p.75-79. 1998.

Ripoli, T.C.C. Ensaios e certificação de máquinas para colheita de cana-de-açúcar. In: Mialhe, L.G. Máquinas agrícolas: ensaios e certificações. Piracicaba: FEALQ, 1996, p.636-674.
Rotz, C.A.; Muhtar, H.A. Rotary power requirements for harvesting and handling equipment. Applied Engineering in Agriculture, St. Joseph, v.8, n.6, p.751-757. 1992.

Santos, M.L.; Braga, M.J. Aspectos econômicos. In: Vieira, C.; Paula Júnior, T.J.; Borém, A. Feijão - Aspectos gerais e cultura no estado de Minas Gerais. Viçosa: Editora UFV, 1998. p.19-53.

Silva, J.S.; Queiroz, D.M. Colheita, trilha, secagem e armazenagem. In: Vieira, C.; Paula Júnior, T.J.; Borém, A. Feijão - Aspectos gerais e cultura no estado de Minas Gerais. Viçosa: Editora UFV, 1998. p.559-585.

Skromme, L.H. Progress report on twin rotor combine concept of rotary threshing and separation. In: International Grain and Forage Harvesting Conference, 1, 1977, St. Joseph. Proceeding... St. Joseph: ASAE, 1977. p.188-191.

Smith, J.A. Dry Edible bean field harvesting losses. Transactions of the ASAE, St. Joseph, v.29, n.6, p.1540-1543, 1986. 